\title{
APplication of Wire ANd ARC AdDitive MANUfaCturing FOR FABricATION OF DUPLEX STAINLESS STEEl ProduCt
}

\author{
Nikola Knezović*, Angela Topić, Ivica Garašić \& Ivan Jurić
}
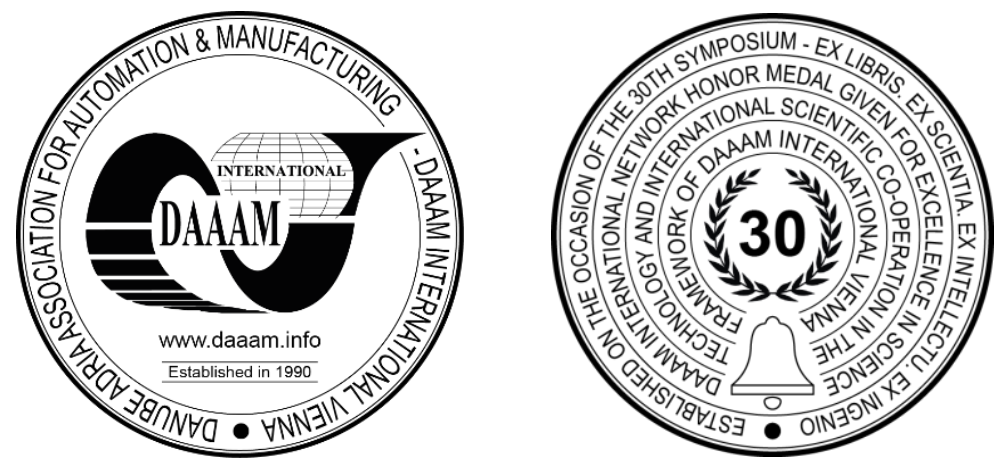

This Publication has to be referred as: Knezovic, N[ikola]; Topic, A[ngela]; Garasic, I[vica] \& Juric, I[van] (2019). Application of Wire and Arc Additive Manufacturing for Fabrication of Duplex Stainless Steel Product, Proceedings of the 30th DAAAM International Symposium, pp.0599-0604, B. Katalinic (Ed.), Published by DAAAM International, ISBN 978-3-902734-22-8, ISSN 1726-9679, Vienna, Austria

DOI: $10.2507 / 30$ th.daaam.proceedings.081

\begin{abstract}
Additive Manufacturing (AM) is a technique where freeform structures are produced by building up material layer by layer. Mostly, AM technologies use powder material as feedstock and different heat sources, which can lead to different problems during the process. WAAM (Wire and Arc Additive Manufacturing) is a technology which has been investigated in the last 30 years, although the first patent was introduced almost 100 years ago. It is a combination of welding and additive manufacturing technologies and one of the potential future application of this technology could be producing the duplex stainless steels. Their excellent corrosion resistance and high mechanical strength make them a favourable choice for oil and gas industrial sectors or off-shore applications. However, they are more difficult to machine than other stainless steels due to their high strength and high work hardening rate, but WAAM could solve some of the problems which occur in their production. Possibility of producing duplex stainless steel product using WAAM is investigated in this paper. Different sets of welding parameters were tested until the most optimal one was chosen, and WAAM product (wall) was made with MIG welding method, using the robotic station.
\end{abstract}

Keywords: Welding; Additive manufacturing; Robotic hand; Duplex stainless steel; Porosity

\section{Introduction}

\subsection{WAAM (Wire and Arc Additive Manufacturing)}

Thanks to the development of modern industries, there is always a continuous need for investigating and developing new technologies. One of the most popular research areas lately is the area of additive manufacturing (AM) technologies. They are different from conventional machining technologies in its very basis - the material is not cut or substracted, but it is added in a layer-by-layer fashion. Basic AM system consists of a combination of a motion system, heat source and the feedstock. AM technologies mostly use only polymer materials or powdered metal, which is not always enough to make a fully functional product. Development of WAAM offers the solution for solving some issues related to other AM technologies. The first WAAM patent dates from 1925, but it has only became popular in the last 30 years, thanks to the development of the modern welding machines [1]. WAAM uses metal welding wire as a feedstock and electric arc as the 
heat source, which makes it a sort of combination of welding and AM technology. Basically, one can combine ordinary welding equipment (power source, welding torch and wire feeding system) with a robotic hand or CNC machine which will be used to move the torch and wire feeder. It is a promising technology for producing fully functional metal products (mostly components for the aerospace industry). High deposition rate (from 50-130 g/min), low cost, safe operational work and fact that parts are almost unlimited by size (the only limit is the size of the operational area of the robotic hand or CNC machine) makes it desirable [2], [3].

However, there are still some issues which occur and challenges to be resolved. Mostly they are welding-related problems, like the residual stresses, distortion (due to excessive heat input), anisotropic mechanical properties, relatively poor part accuracy and surface finish (post-processing is needed almost always) [1], [4], [5]. Some of these problems are already reduced, but there are still problems for future investigations.

WAAM starts the same way as any other AM technology, with designing the 3D CAD model. Some certain software intended for that can be used, or even the modern reverse engineering processes (like 3D scanning) [6]. The designed part is then saved in some standard format (usually .stl). That file is a basis for slicing part into layers. Layer's contour (it is negligibly thin, so it is called 2D contour) is used for generating the tool (welding torch) path. That is followed by choosing proper welding parameters (welding current, wire-feed rate, welding speed, etc.) and bead modelling. Using generated path and chosen welding parameters, the product is then made in layer-upon-layer fashion - the first layer is deposited on the base plate (substrate), torch moves up for suitable height and deposits the second layer onto it, and the process continues like this until all layers are deposited and the whole part is made. Post-process machining path can also be generated [7], or post-processing can be done independently. Some general WAAM system with its main features is shown in Fig.1.

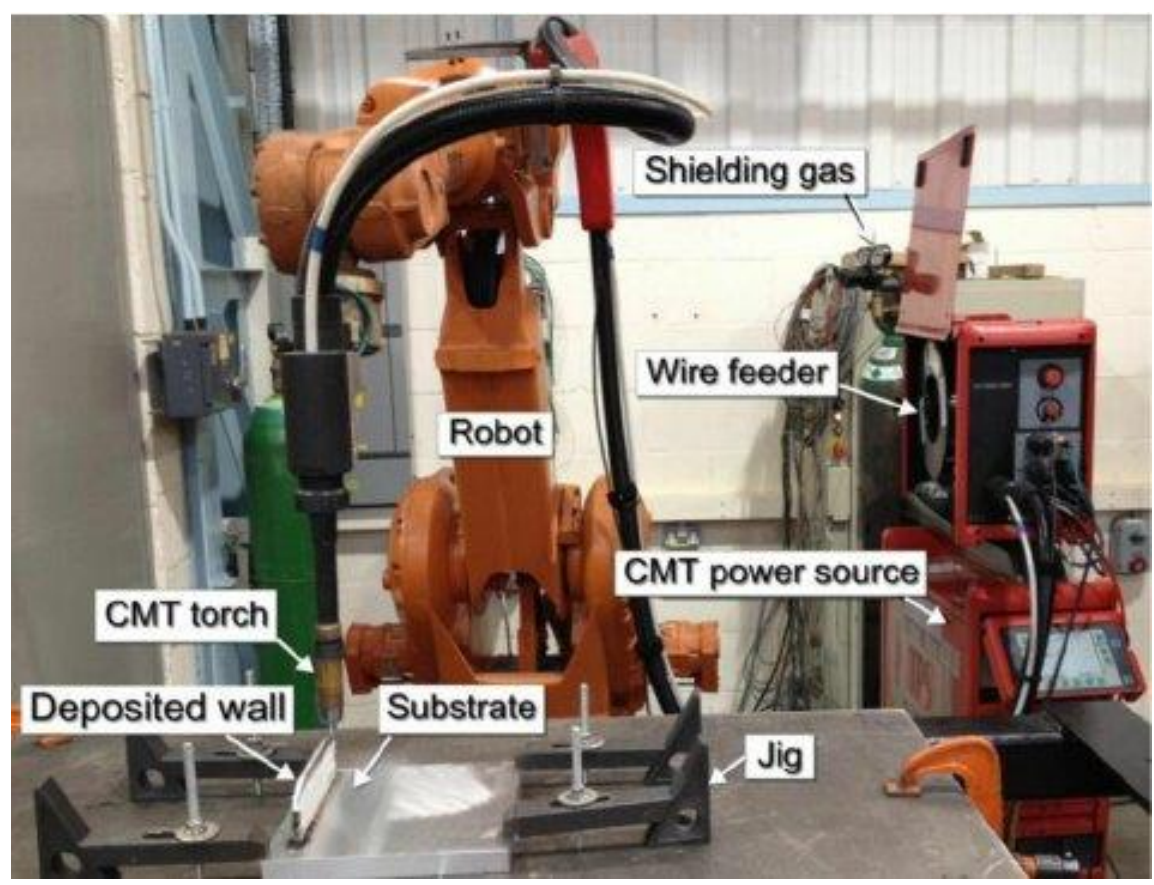

Fig. 1. Basic WAAM system [8]

\subsection{Duplex stainless steels}

Stainless steels are the group of steels mostly known for their great corrosion resistance, thanks to which they got their name. They are corrosion resistant due to the presence of chromium-rich oxide film which forms naturally on their surface and it is self-healing if there is enough oxygen available. According to their microstructure, they can be martensitic, ferritic, austenitic or duplex (austenitic/ferritic) [9]. Due to their mixed microstructure (about 50\% of austenite and 50\% of ferrite), group of duplex stainless steels is most popular for investigation and research, since they combine best properties of the ferritic and the austenitic stainless steels. They primary solidify as ferrite and, as the temperature falls during cooling, ferrite partially transforms to austenite [10].

They were produced first in Sweden in 1930. These first-generation had good performance characteristics, but some welding-related problems have been recorded. For example, the HAZ (heat affected zone) and welded metal had lower corrosion resistance than that of the base metal and significantly lower toughness due to excessive ferrite [11].

Duplex stainless steels are usually divided into five groups nowadays (their alloy content determines their corrosion resistance). They are ranging from the lower alloyed lean grades to highly alloyed hyper duplex grades [12]. The most used are the ones called standard duplex steels, with around $22 \%$ of chromium and $3 \%$ of molybdenum. A representative of this group is grade 2205 (according to AISI) or 1.4462, which covers almost $60 \%$ of all duplex use [11], [13]. 


\subsection{The motive for the research}

Engineering materials are evaluated mostly by the possibility to produce different parts using them, with optimal cost and minimum problems during fabrication. That is a limitation for duplex stainless steels, due to problems and difficulties which occur during welding and machining. Welding is quite difficult because of alloying elements and repeated cycles of heating and cooling which cause the formation of detrimental intermetallic phases, particularly in highly-alloyed grades [12], [14], [15]. These precipitations change the austenite/ferrite ratio which leads to lower corrosion resistance. They are also difficult to machine, because of low sulfur content, high yield strength and high work-hardening rate [11].

However, WAAM technology is able to produce almost fully functional and near-net-shape products which only needs some additional machining as post-process and it could be a solution as an innovative technology for fabrication of duplex stainless steel parts. WAAM has an advantage of using welding wire solely so there is no need to look for matching additional material which could at least reduce welding-related issues. If correct welding parameters were chosen and gas shielding is appropriate, it could reduce additional post-process machining.

WAAM has its own problems just like any other technology, which is already mentioned, but if it is possible to produce duplex stainless steel parts with the stable process, then it is worth trying to conduct further researches which will offer a solution for some issues. The objective of this study was to investigate the possibility of fabrication duplex stainless steel parts using WAAM technology and to understand the relationship between welding parameters and product properties.

\section{Experimental procedure}

An experiment was carried out in Welding Laboratory at the Faculty of Mechanical Engineering and Naval Architecture, University of Zagreb. WAAM system was designed particularly for this experiment and it was made combining welding robot station (Daihen Varstroj) and robotic hand OTC Almega AX-V6 (six axes of freedom) with MIG welding machine DP-400 and wire feeder CM-7401. Additional material was 1.2-mm diameter duplex stainless steel wire (1.4462 or AISI 2205). Shielding gas was Inoxline C2 (containing 97.5\% Ar and 2.5\% $\mathrm{CO}_{2}$ ). Base material was 1.4301 (AISI 304) stainless steel plate, 300x150x8mm.

First goal was to find an appropriate set of welding parameters to produce bead which will fulfil some important requirements. The layer should be at least $7 \mathrm{~mm}$ wide, to provide enough thickness after post-process machining. Welding arc and process had to be stable and smooth. Finally, arc energy for this duplex stainless steel grade should be at least 0.4 $\mathrm{kJ} / \mathrm{mm}$, calculated using (1):

$$
A E[\mathrm{~kJ} / \mathrm{mm}]=\frac{I \cdot V \cdot 60}{1000 \cdot v}
$$

where I is welding current, $\mathrm{V}$ is voltage and $\mathrm{v}$ is welding speed. Numerous combinations of parameters were tried, but only four of them fulfilled the mentioned requirements. These sets are shown in Table 1.

\begin{tabular}{|c|c|c|c|c|}
\hline Label & Welding current [A] & Voltage [V] & Welding speed [cm/min] & Layer width \\
\hline A & 140 & 17 & 25 & 7.5 \\
\hline B & 125 & 17 & 22 & 8 \\
\hline C & 125 & 17 & 25 & 7 \\
\hline D & 130 & 17 & 25 & 7 \\
\hline
\end{tabular}

Table 1. Sets of welding parameters for try-outs

Widest layer was produced with set B, but some arc instability was recorded during the process, and some humps on the layer could be clearly seen later. A similar situation was with set A. This probably occurred due to high current (set A) and low welding speed (set B). Stable arc was obtained using sets C and D, but after the deposition, it could be seen that set D provided layer which looks much smoother than any other, so this set was chosen for further experiments. These layers are shown in Fig. 2.

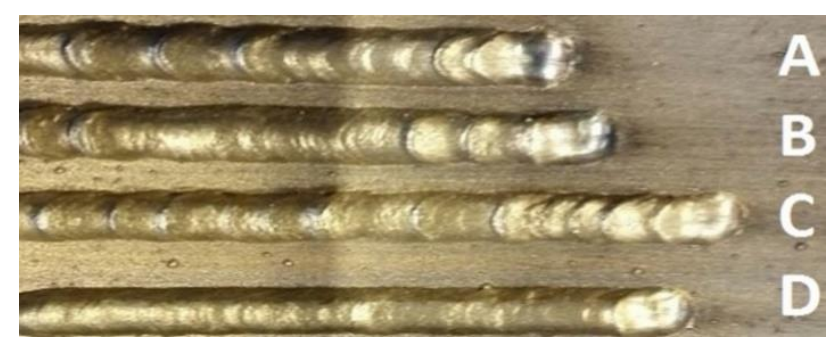

Fig. 2. Layers deposited with a different combination of parameters 
Next step was to produce the first five layers of the part with given parameters, but some issues occurred immediately at the beginning of the second layer deposition. Humps were even more obvious than with test parameters, and the arc was slightly unstable. A possible reason could be the heat loss, which was slower than it was during the first layer deposition (base plate takes away a great amount of heat at the start, so heat goes away faster for the first layer). With every following layer, heat loss is slower and problems with humps and arc instability are worse. To compensate that, welding speed was increased to $26 \mathrm{~cm} / \mathrm{min}$ for the second layer and $27 \mathrm{~cm} / \mathrm{min}$ for the third one. The process was more stable with these values. However, greater speed cause lower arc energy, so $27 \mathrm{~cm} / \mathrm{min}$ had to be kept as upper value for every following layer.

With this improvement, final parameters could be selected and inserted into the robot welding program. The base plate was brushed, cleaned and degreased using $96 \%$ ethanol solution. The wire was deposited layer by layer with a single bead, using the neutral technique without weaving. After one layer was finished, the deposition direction was reversed for the next one (one would start on the left side, next one on the right, etc.) to reduce distortions on both ends of the part. Also, the torch was moved up for $2.5 \mathrm{~mm}$, which was the average height of the layers measured during the experiments. The time delay between deposition for two subsequent layers was one minute, just how much is needed to clean the latest layer before the next one is deposited. 30 layers were deposited in one hour and 15 minutes, and the produced part (wall) was $66 \mathrm{~cm}$ high. It is shown in Fig. 3., before (a) and after additional machining (b).

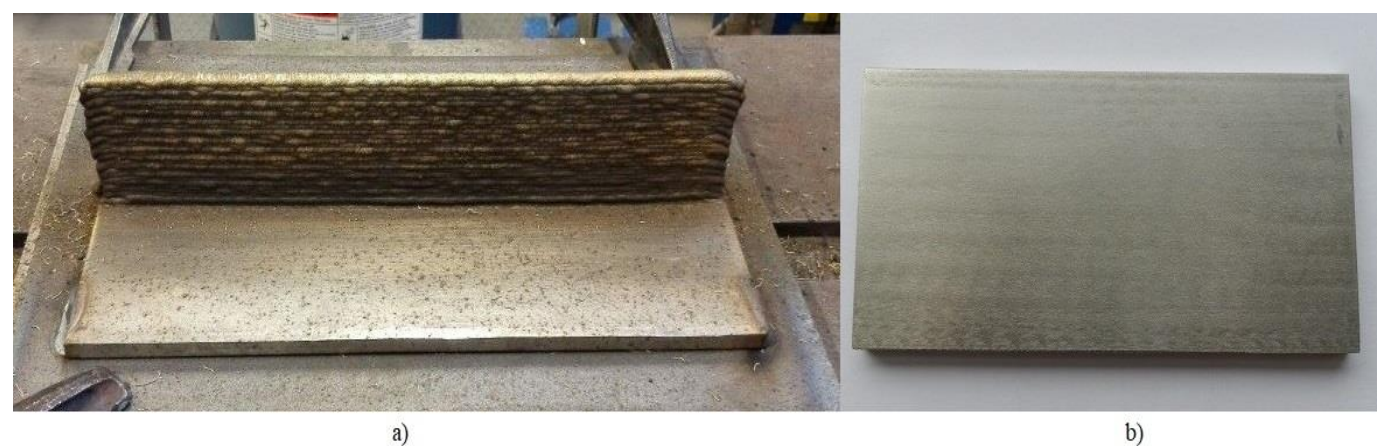

Fig. 3. WAAM duplex stainless steel part

\section{Results and discussion}

The final product had satisfying geometric characteristics. It managed to stay perpendicular to base plate plane and it did not bend left or right. Distortions have not appeared in these directions, which means the robotic hand is a good solution for fabricating similar parts. Problems with distortion occurred only along the z-axis (vertical). During the process, layers were "pulling" the base plate up more than it was expected and this should not be acceptable. To avoid this problem in future researches, more rigid clamping or thicker base plate should be used. There was also no significant surface waviness or height deviations across the length, except on the ends where the mentioned problems with vertical distortion occurred. However, this issue with distortion would be even worse if the deposition had started from the same side for every layer. Reversing its direction after every pass reduced excessive accumulation of defects on the wall edges.

Unexpectedly, the total height was cca. $60 \mathrm{~mm}$ after 30 layers. Average layer height was $2.5 \mathrm{~mm}$ during the initial experiments, so that was the value chosen as input for the robot to raise the torch vertically after every layer. Obviously, layer height is becoming lower after certain passes. It happens because more wire melts on the wall lateral sides at the latter passes. It does not affect wall width significantly, but a change in the height is obvious. Future researches should include measuring every layer height as a necessary requirement in order to provide better results.

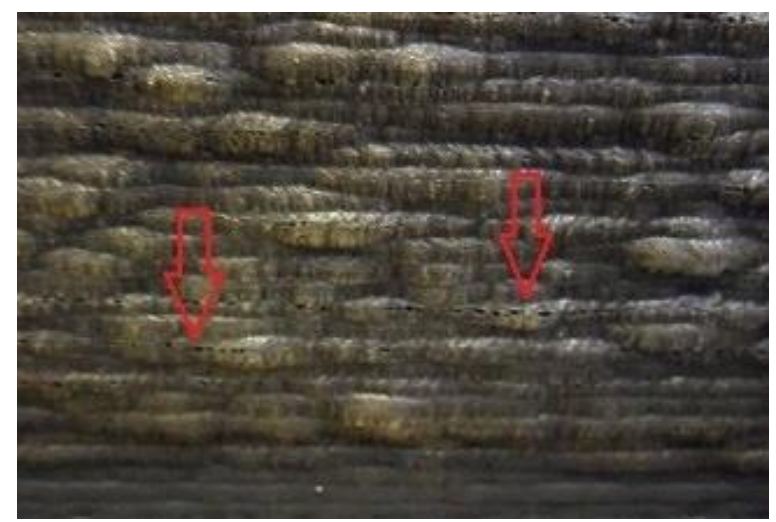

Fig. 4. Pores on the lateral sides of the wall 
The greatest issue (which can be seen even by naked eye) is porosity. They could be seen on lateral sides of the wall, especially at higher layers (Fig. 4., pointed with red arrows). This happens probably because while the welding torch is still low (for the first five or six layers), base plate deflects shielding gas, thus creating a pool which protects first few passes. At the higher layers, shielding gas is lost in the surrounding air and does not provide enough protection. However, these pores are shallow and only affects the surface. Fig. 4. (b) shows part after additional machining, and it can be clearly seen that pores have not damaged material inside. Considering that, porosity should not be an issue when making thin structures, but when the part with thicker wall should be produced, layer overlapping is necessary and these pores could occur between two contiguous layers, which could lead to the appearance of the porosity in the inside of the part. Solution for this problem could be the introducing of the additional lateral gas nozzles which would provide shielding gas environment surrounding the product.

\section{Conclusion and suggestions}

The main goal of this article was to demonstrate there is a possibility to produce near-net-shape parts made of duplex stainless steel using WAAM technology, with the stable process and with an acceptable range of welding parameters. Since it has been proven, some of the main conclusions are:

- there was no distortion in a plane perpendicular to the base plate, which means the robotic hand is a suitable solution to provide torch moving;

- distortions occurred in the vertical direction and there is clearly a need for better clamping solution;

- reversing direction after every layer is inevitable to reduce vertical distortion;

- layers' height becomes lower after certain passes since wire melts more to the lateral sides, so measuring only the first few layers is not a reliable data to work with;

- porosity on the lateral sides is the main issue, and a better solution to provide shielding gas (especially for thicker parts) is necessary.

Suggestions for potential further researches are numerous, but some of the most interesting in order to develop better duplex stainless steel product are:

- testing of the austenite/ferrite ratio to examine is there an excessive ferrite amount;

- testing of the most important mechanical properties to check are they comparable and compliable to appropriate standards;

- corrosion resistance testing.

\section{References}

[1] Williams, S., Martina, F., Addison, A.C., Ding, J., Pardal, G. \& Colegrove, P. (2016). Wire + Arc Additive Manufacturing, Materials Science and Technology, Vol. 32, No. 11, 2015, pp. 641-647., ISSN: 0267-0836, 10.1179/1743284715Y.0000000073

[2] Ding, D., Pan, Z., Cuiuri, D. et al. (2015). Wire-feed additive manufacturing of metal components: technologies, developments and future interests, The International Journal of Advanced Manufacturing Technology, Vol. 81, No. 1-4, pp. 465-481., 2015, ISSN: 1433-3015, 10.1007/s00170-015-7077-3

[3] Ding, J., Martina, F., \& Williams, S. (2015). Production of large metallic components by additive manufacture issues and achievements, Proceedings of "Metallic Materials and processes: industrial challenges", Deauville, France, November 25-27, 2015

[4] Donoghue, J., Antonysamy, A.A., Martina, F., Colegrove, P.A., Williams S.W., \& Prangnell, P.B. (2016). The effectiveness of combining rolling deformation with Wire-Arc Additive Manufacture on $\beta$-grain refinement and texture modification in Ti-6Al-4V, Materials Characterization, Vol. 114, April 2016, pp. 103-114., ISSN: 10445803, 10.1016/j.matchar.2016.02.001

[5] Martina, F., Colegrove, P.A., Williams, S.W., \& Meyer, J. (2015). Microstructure of interpass rolled Wire + Arc Additive Manufacturing Ti-6Al-4V components, Metallurgical and Materials Transactions A, Vol. 46, No. 12, 2015, pp. 6103-6118., ISSN: 1543-1940, 10.1007/s11661-015-3172-1

[6] Ding, D., Pan, Z., Cuiuri, D., Li, H., Larkin, N. \& Van Duin, S. (2016). Automatic multi-direction slicing algorithms for wire based additive manufacturing, Robotics and Computer-Integrated Manufacturing, Vol. 37, Issue C, February 2016, pp. 139-150., ISSN: 0736-5845, 10.1016/j.rcim.2015.09.002

[7] Ding, D., Shen, C., Pan, Z., Cuiur,i D., Li, H., Larkin, N., et al. (2016). Towards an automated robotic arc-weldingbased additive manufacturing system from CAD to finished part, Computer-Aided Design, Vol. 73, April 2016, pp. 66-75., ISSN: 0010-4485, 10.1016/j.cad.2015.12.003

[8] Cong, B., Ding, J., \& Williams, S. (2014), Effect of arc mode in cold metal transfer process on porosity of additively manufactured Al-6.3\%Cu alloy, The International Journal of Advanced Manufacturing Technology, Vol. 76, No. 9-12, 2015. pp. 1593-1606., ISSN: 1433-3015, 10.1007/s00170-014-6346-X

[9] Karlsson, L. (2004). Stainless steels: past, present and future, Svetsaren, Vol. 1, 2004, pp. 1-6., 0341-4248, https://www.researchgate.net/publication/292870835_Stainless_steels_-_Past_present_and_future/citations 
[10] Topić, A., Bauer, B., Kožuh, Z., \& Knezović, N. (2016). Gas composition influence on the microstructure and geometry of laser-welded joints in duplex stainless steel, Proceedings of $27^{\text {th }}$ International DAAAM Symposium "Intelligent Manufacturing \& Automation", Mostar, ISSN: 1726-9679, ISBN: 978-3-902734-08-2, Katalinic, B. (Ed.), pp. 734-742., DAAAM International, Vienna, 10.2507/27th.daaam.proceedings.106

[11] IMOA (2014). Practical Guidelines for the Fabrication of Duplex Stainless Steels, International Molybdenum Association (IMOA), ISBN-13: 978-1-907470-09-7, London, UK

[12] Karlsson, L. (2012). Welding duplex stainless steels - a review of current recommendations, Welding in the World, Vol. 56, No. 5-6, 2012, pp. 65-76., ISSN: 1878-6669, 10.1007/BF03321351

[13] Vinoth Jebaraj, A., Ajaykumar, L., Deepak, C.R. \& Aditya, K.V.V. (2017). Weldability, machinability and surfacing of commercial duplex stainless steel AISI2205 for marine applications - a recent review, Journal of Advanced Research, Vol. 8, No. 3, 2017, pp. 183-199., ISSN: 2090-1232, 10.1016/j.jare.2017.01.002

[14] Kotecki, D.J. \& Lippold, J.C. (2005). Welding metallurgy and weldability of stainless steels, John Wiley \& Sons, Inc., ISBN: 0-471-47379-0, Hoboken, New Jersey

[15] Yang, J., Wang, Q., Wei, Z., Guan, K. (2014). Weld failure analysis of 2205 duplex stainless steel nozzle, Case Studies in Engineering Failure Analysis, Vol. 2, No. 2, 2014, pp. 69-75., ISSN: 2213-2902, 10.1016/j.csefa.2014.05.001 